\title{
The Chess Theory and Cultural Characteristics of Chinese Intangible Cultural Heritage "Jiu" Chess
}

\author{
Xiaoming Ma1', Wanqi Li', Awang Bianba² \\ ${ }^{1}$ Qinghai Nationalities University, Xining, China \\ ${ }^{2}$ Tibet Tibetan Chess Association, Lhasa, China \\ Email: 592707294@qq.com
}

How to cite this paper: Ma, X. M., Li, W. Q., \& Bianba, A. (2021). The Chess Theory and Cultural Characteristics of Chinese Intangible Cultural Heritage "Jiu" Chess. Advances in Physical Education, 11, 82-88. https://doi.org/10.4236/ape.2021.111006

Received: January 5, 2021

Accepted: February 22, 2021

Published: February 25, 2021

Copyright (c) 2021 by author(s) and Scientific Research Publishing Inc. This work is licensed under the Creative Commons Attribution International License (CC BY 4.0).

http://creativecommons.org/licenses/by/4.0/

\begin{abstract}
National and folk chess games are an important part of Chinese traditional culture. From the perspective of intangible culture, it is difficult to analyze the principles and cultural characteristics of "Jiu" chess, especially its basic principles and methods. The study of the history of the "Jiu" chess, the basic steps and the graphic formation of the move, and the value and function of the "Jiu" chess in the contemporary era can better explain the new value of the intangible cultural heritage culture.
\end{abstract}

\section{Keywords}

"Jiu" Chess, Cultural Heritage, Cultural Characteristics, Intangible Cultural Heritage

\section{(c) (i) Open Access}

\section{Introduction}

The folk chess game is a kind of game based on the chessboard. The square inch chessboard has the function of edifying people's sentiment, tempering people's will quality and leisure and entertainment. The chess culture in China's history is long and brilliant, with a variety of types and strong interest. It has been loved by people for thousands of years. Tibetan is a member of the big family of the Chinese nation, and its folk traditional chess is an excellent national folk cultural heritage.

With a history of more than 1000 years (Ma, 2020), Tibetan chess is divided into two major categories of "Mimang" and "Jiu" chess. Among them, Mimang is very similar to "Wei" chess, commonly known as Tibetan go, while "Jiu" chess has similar rules with international checkers, so its game has strong ornamental 
and interesting. "Jiu" chess is popular in Northwest China, which is a very representative traditional culture of Tibetan nationality. "Jiu" chess is a large category, including many small chess categories. According to the excavation and sorting out by the Tibetan Chess Association of China, there are 29 kinds of chess that have been taught and dozens of kinds of chess to be developed ( $\mathrm{Ma}$, 2020). "Jiu" chess is the core of Tibetan chess. It has a unique charm and stimulates the imagination and creativity of chess lovers.

\section{The Historical Origin of "Jiu" Chess}

As for the origin of Tibetan chess, there are three kinds of views in history, that is, native speaking, southern speaking and Western speaking. From the current historical facts and literature, there is no record about the origin of "jiu" chess, and there is still controversy. However, we can learn from the scattered papers and Tibetan chess stories that: In the past, Tibetan chess "only played among nobles, monks, rich families and officers". According to the source of Tibetan chess "Jiu" chess, "Jiu" chess has a great similarity with the "square chess" of "lost square" popular in many areas of China (Zhala \& Zaxi, 2007). Dawa Sangbu said in "why Mimang is called Tibetan" Wei "chess": As early as 1400 years ago, "Mimang" appeared in Tibetan classics. Therefore, the exact historical data and cultural relic demonstration still need to be discovered and excavated in the future. Generally speaking, the cognition and focus of the origin of "Jiu" chess are local origin and introduction of Han area. There is also a folk saying: "Jiu" chess was born in the mysterious ancient divination ceremony, and experienced the development process from royal court to folk. This paper, written by American Tibetan scholar Peter Sauter and compiled by Dekang sorangqujie, deputy editor of Tibet studies, also describes the origin of Tibetan chess. The paper is published in Japanese "Wei" chess and American "Wei" chess research. It holds that chess has been popular in China's inland and Tibetan areas since ancient times, which is mainly based on the Han Tibetan calendar Analysis and Research on historical materials, folklore or chess skills and habits (Ma \& Shang, 2017a). "Jiu" chess is popular in most parts of Northwest China. The difference is that the appellation is different. In Amdo, Tibetan chess is called "Jiu" chess is a note translated from Tibetan into Chinese, which retains and accumulates a very heavy cultural element.

\section{The Theory and Expression of "Jiu" Chess}

\subsection{Tools of "Jiu" Chess}

1) Chessboard

The chessboard is composed of 14 equal distance vertical and horizontal parallel lines, forming 196 crossing points, each of which is the place where the drop is made (Sun, 2018). The square in the middle of the chessboard has a diagonal line. The two ends of the diagonal line are the places where the first piece is dropped by both sides at the beginning of the game (see Figure 1). 


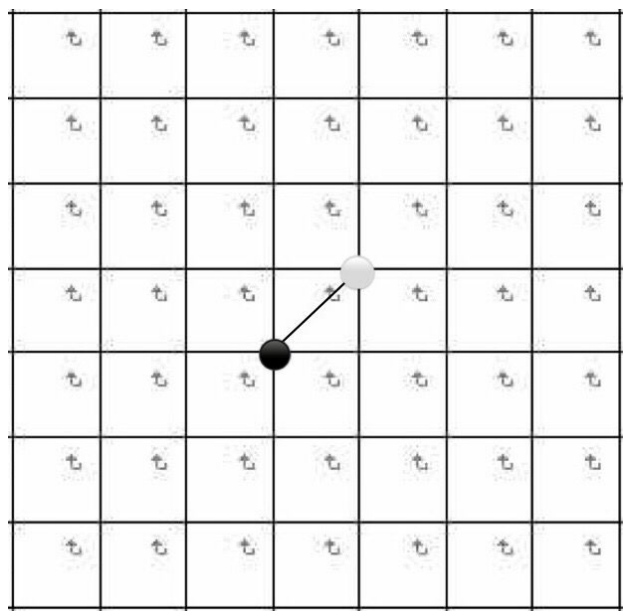

Figure 1. Pieces of "Jiu" chessboard.

\section{2) Chess pieces}

The pieces are divided into black and white, and the shape is oblate. The number of pieces is at least 98 sunspots and 98 white characters.

\subsection{The Game and Victory of "Jiu" Chess}

\subsubsection{Playing Chess}

1) At the beginning of the game, both sides of the game hold the same color of chess pieces and take turns to play chess.

2) When playing chess, the two sides first put pieces into the empty space, white first and then black. The opponent can use the pieces to form a "Jiu" chess formation or destroy the opponent's formation.

3) When the chessboard is full of pieces, the two sides exchange chess boxes according to etiquette, black first white, then remove the pieces of the opposite party at both ends of the square diagonal in the middle of the chessboard (Ma \& Shang, 2017b).

4) Method of playing chess:

a) Move the pieces. Move a piece from one crossing point to another adjacent empty crossing point, only one space at a time;

b) Cheng Fang eats seeds. Move one's own pieces and move them in different ways to form different kinds of "Jiu". Then remove the opponent's pieces from the chessboard according to the rules and put them into the box;

c) Jump and eat. Move your own piece, skip one of the other's pieces, and remove the other's pieces. Can jump, stop at any time, so as to stop in their own position, cannot jump two or more pieces at a time.

5) Tail disk flying rule

When a party's pieces are equal to or less than the number of chessboard paths, the chess pieces of that party will become flyers. The flyers can move freely on the chessboard without the limitation of the number of moving steps. However, the one who does not become a flyer is limited by the number of moving steps. 
In the flying stage, both sides are not allowed to eat only one piece.

In the flying stage, after making different types of "Jiu", one or more seeds can be eaten, or two or more children can be jumped.

When there are only three left in a party, you can eat one at a time.

\subsubsection{Win or Lose}

1) When one side has less than or equal to three pieces, and the other side can form at least three "Jiu" shapes, the one with fewer pieces is negative.

2) Although there are many pieces on one side, but they cannot move, then one side of the chess pieces cannot be moved.

\subsection{The Basic Form Terms of "Jiu" Chess}

Jiu: square. As shown in Figure 2, the four corners of a chess lattice of bit a are occupied by the same kind of chess pieces, forming a square.

Ji: the smallest square, which means "a square", as shown in Figure 2.

Ni: two squares. As shown in $a+b$ in Figure 2.

Song: three squares, as shown in $\mathrm{a}+\mathrm{b}+\mathrm{c}$ in Figure 2.

$\mathrm{Xi}$ : four squares, as shown in $\mathrm{a}+\mathrm{b}+\mathrm{c}+\mathrm{d}$ in Figure 2 .

In turn, it can be up to $\mathrm{Gu}$ (nine squares) and so on.

Preparation: the shape that has been prepared for a "Jiu" is called preparation.

Fight "Jiu": "Jiu" formation process is called Fight "Jiu". As shown in Figure 2 , the key to playing for Fight "Jiu" is the chess piece playing " $X$ ".

Big, small and medium King Kong shape: it is a chess shape that needs to be formed as far as possible when placing pieces. They are conducive to the formation of various "Jiu" or good formation. On the other hand, we need to destroy each other's shapes as much as possible.

\subsection{The Layout of "Jiu" Chess}

1) Put the pieces on the chessboard in the order of white first and then black.

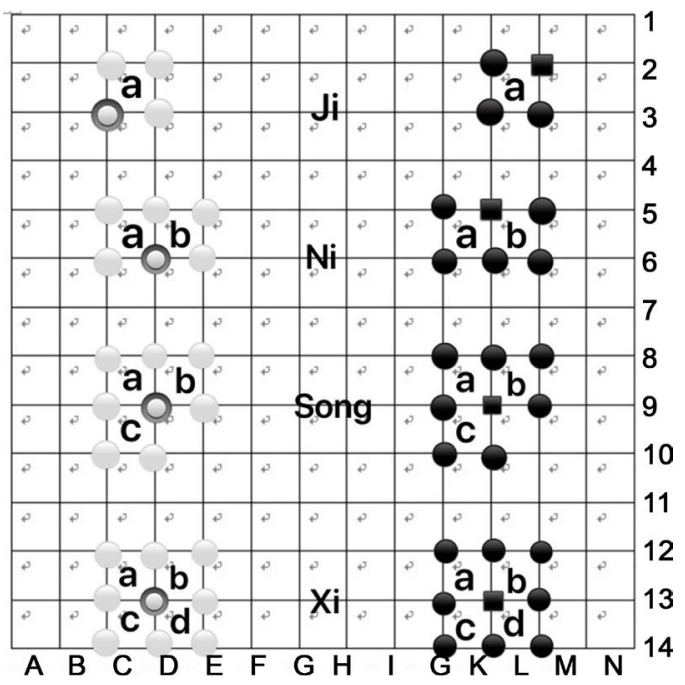

Figure 2. The shape of "Jiu" Chess is Ji, Ni, Song and Xi. 


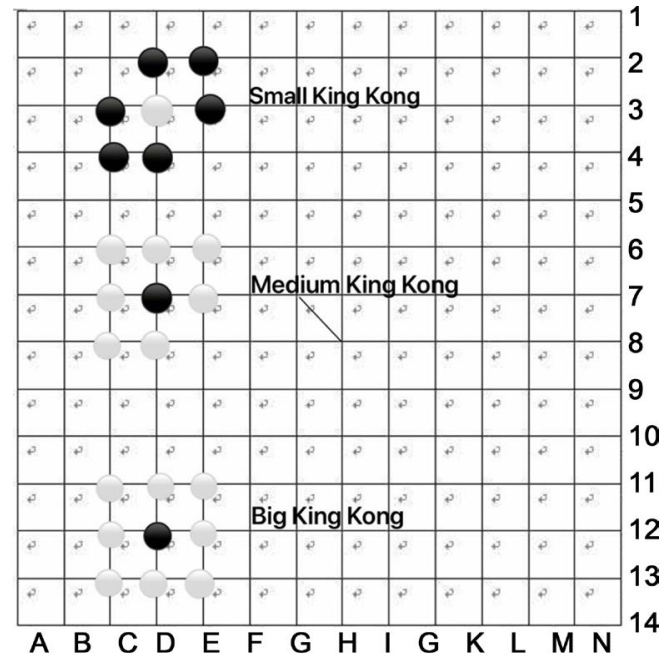

Figure 3. The big and small King Kong in the shape of "Jiu" Chess.

2) The release must start at both ends of the diagonal line in the center of the chessboard.

3) The placed pieces cannot be moved, and cannot be lifted in the stage of placing pieces.

4) After the chessboard is full, the two sides will remove the corresponding pieces of each other according to the number of times they have completed.

5) When putting pieces, you should try to keep your pieces together, or let the pieces of the other party scatter as much as possible. Let yourself form "Gougu" (hook eye, three pieces on the three corners of a chess box) (see Figure 3).

\section{Cultural Characteristics and Inheritance of Tibetan Chess}

The spread of Tibetan chess retained the original way of survival. In the long-term development and inheritance process, Tibetan chess has always been spread in the upper class society. Due to historical reasons, Tibetan chess was not popularized among the general public in the early days, and gradually spread to the public in modern times. "Jiu" Chess is a typical representative of Tibetan nationality's integration and innovation of foreign culture, and it is also an exhibition of Tibetan nationality's openness and wisdom. The main features are as follows:

1) The naturalness of chess culture

Nature provides the conditions for human beings to create culture. At the same time, people who create culture create their favorite games according to their own instinctive biological attributes. After continuous development and evolution, it has pursued high-level cultural activities. Most Tibetan chess activities are carried out in the wild. Branches, small stones, and even sheep dung eggs can be used as chess pieces. The entertainment of playing chess is not subject to any restrictions. It is very casual and comfortable.

2) Universality and variability of chess culture

Each nation has its own unique culture, so culture has its own nationality. The 
culture of each nation will affect other ethnic groups in the process of inheritance and transmission, especially the interesting game activities are easy to be accepted by the surrounding ethnic groups. Simulation and learning will produce variability in the inheritance. The spread and continuation of chess culture form the basic form of inheritance. Universality and variability form cultural innovation and promote development. They are dialectical unity. Therefore, the universality and variability of chess culture is the link and opportunity of cultural development.

In 2006, the first Tibetan chess performance competition was held in Qinghai, China. In the same year, Tibetan chess was listed as the first batch of intangible cultural heritage list of Qinghai Province, which was highly valued by the Ministry of culture. Financial and human resources were given to rescue and protect it. The inheritor of "Jiu" chess was established, and the plan of opening classes to teach was used to develop Tibetan chess.

In recent years, Tibet, Qinghai, Yunnan, Sichuan, Gansu, Xinjiang and other Tibetan Chess Association organizations are aware of this situation, launched the protection of Tibetan chess culture, relevant personnel began to visit, village investigation, collection, sorting out a large number of first-hand information [ ] In particular, Tibet Tibetan Chess Association has actively raised funds and successfully introduced Tibetan chess into the extracurricular activities of local primary and secondary schools, protecting this precious cultural heritage project accurately and effectively.

In September 2019, Tibetan chess was included in the performance category at the national minority sports meeting, and won the third prize. This shows that Tibetan chess has gone to the national arena, and the latter goal is to enter the competition category. Now the Internet + has been involved in chess activities, which will highlight the epochal nature of cultural heritage and give Tibetan chess new historical characteristics.

To sum up, through a comprehensive analysis of the existing literature and the basic characteristics of the "Jiu" chess pattern, together with the score of the multi-board chess matches in recent years, we can see that the "Jiu" chess has a very scientific principle of moving chess, especially in the final game "flying pieces" stage more changes, often appear obvious weakness in the case of the turnover victory, the charm is endless. The "Jiu" chess has integrated into the unique and mysterious material and spiritual culture of the Tibetan people, and has formed a unique national spirit that fully demonstrates the Tibetan people's national psychology, spiritual belief and pursuit, and has developed the "Jiu" chess culture to clarify the classification of the Tibetan "Jiu", more conducive to the protection and inheritance of Tibetan chess culture.

\section{Funds}

This work is supported by General projects of National Social Science Foundation (No. 17BTY111). 


\section{Conflicts of Interest}

The authors declare no conflicts of interest regarding the publication of this paper.

\section{References}

Ma, S. H. L., \& Shang, T. (2017a). Inheritance and Protection of Tibetan Chess Culture. Tibet Studies, 4, 157-160.

Ma, X. M., \& Shang, T. (2017b). A Comparative Study of "Mi Mang" and "Jiu" in Tibetan Chess. Journal of Qinghai University for Nationalities (Social Science Edition), 43, 126-131

Ma, Z. H. Y. (2020). Tibetan Chess Can Be Played Like This. Haidong Times, 8, 1-2.

Sun X. (2018). Investigation and Research on the Current Situation of Tibetan Chess Education in Primary and Secondary Schools and the Development of Micro Courses. Beijing: Minzu University of China.

Zhala D., \& Zaxi D.Z. (2007) The Witness of Tibetan Chess Culture: An Academic Report on the Tibetan Stone Chessboard Found at the Jiulin Palace Site in Qiangbamin. Tibet Studies, 2, 37-41. 